\title{
Diagnostic Sacroiliac Joint Injections: Is a Control Block Necessary?
}

\author{
Bruce Mitchell, Tomas MacPhail, David Vivian, Paul Verrills, Adele Barnard \\ Metro Pain Group, Melbourne, Australia \\ Email: abarnard@metrospinal.com.au
}

Received 3 March 2015; accepted 30 June 2015; published 3 July 2015

Copyright (C) 2015 by authors and Scientific Research Publishing Inc.

This work is licensed under the Creative Commons Attribution International License (CC BY). http://creativecommons.org/licenses/by/4.0/

(c) (i) Open Access

\section{Abstract}

Background: Sacroiliac joint (SIJ) pain presents as a deep and somatic pain, predominantly affecting the lower back and buttock and referring down the leg, sometimes as far as the foot. Given that the features of SIJ pain are non-specific and that this referred pain is similar to lumbar facet joint and lumbar disc pain, diagnostic local anesthetic injections (diagnostic blocks) into the SIJ are used to identify the source of pain. Despite wide use, little is known about the false positive rate of a single diagnostic sacroiliac (SI) block and the requirement for a control block. Objective: To determine whether a control SI block is necessary and to monitor the false positive rate for a single injection. Study Design: A prospective and observational study was conducted as part of a practice audit, with data collected over 3.5 years at the authors' private practice. Patients \& Methods: Under fluoroscopic guidance, 1408 consecutive patients presenting with prominent deep somatic pain over the SIJ region were sterilely injected with anesthetic into the SIJ and/or the deep interosseous ligament (DIL). Pain was measured on the 11-point Numerical Rating Scale (NRS) prior to injection and incrementally over the following 1- 2 weeks. Fully completed and unequivocal data sets were available for 1060 patients. Decreases in pain scores (of $>80 \%$ ) at $>2$ hours of postinjection were indicative of SIJ pain and recorded as a positive SIJ block. Results: Of 1060 patients receiving a first SIJ diagnostic block, $680(64.1 \%)$ recorded a positive result. Subsequently, 271 positive patients and 22 who were negative for SIJ pain opted to receive a second control block. SIJ pain diagnosis was confirmed in $237 / 271(87.5 \%)$ of those with an initial positive response, while $18 / 22$ patients $(81 \%)$ had their initial negative result confirmed. The false positive rate of a single block is therefore calculated at $12.5 \%$, and on a contingency table analysis, a single anesthetic SIJ injection has diagnostic accuracy of $87.03 \%$, with high sensitivity $(98.3 \%)$, when compared with a second control diagnostic block. Limitations: All injections were performed at one clinical centre. A proportion $(348 / 1408)$ of initial patients did not return fully completed pain records or had equivocal responses ( $\geq 80 \%$ pain relief, but transiently, for $\leq 30 \mathrm{~min}$ ) and were excluded from further analysis. Conclusion: Given the observed high rates of accuracy in this study, it is reasonable to suggest the use of one diagnostic block as the criterion standard for assessing the SIJ as 
the source of a patient's pain.

Keywords

Sacroiliac Joint, Pain, Diagnostic Injection, Control Block, Sensitivity

\section{Introduction}

The sacroiliac joint (SIJ) is innervated, and upon provocation it has been shown to produce low back pain that can radiate into the leg. Such referred pain can be relieved by local anesthetic infiltration into the SIJ, and thus there is prima facie evidence that the SIJ can be a source of pain. Decades of basic science and clinical research support this contention [1]-[6] and the use of anesthetic injections, or diagnostic blocks, which have specifically demonstrated that the SIJ is the source of pain in $15 \%$ to $38 \%$ of all presentations of low back and referred buttock/leg pain [7]-[10]. Across a range of settings, using controlled blocks and a pain relief criterion of at least $50 \%$, the prevalence of SIJ pain ranges from $10 \%$ to $62 \%$, though a majority of analysed studies in recent systematic reviews indicate a point prevalence of around 25\% [11] [12].

SIJ pain is somatic by nature, which can be characteristically deep and aching. It is also frequently associated with referred pain, with effects in the buttock and thigh most common (seen in $94 \%$ and $48 \%$ of cases, respectively), though referral to the lower leg, foot, ankle and groin all occur. These patterns may lead to a mistaken diagnosis of referred pain from an intervertebral disc or facet joint [13]-[15], despite the difference in pain quality and distribution, due to lumbar or sacral radicular pain [15] [16]. SIJ pain rarely extends above L5, and is most importantly characterized by focal pain over the posterior superior iliac spine [7].

While the SIJ is commonly described as a diarthroidal synovial joint, only the anterior third of the junction is a true synovial joint, with the remainder comprised of ligamentous connections, notably those formed by the interosseous sacroiliac ligament at the posterior joint border [17] [18]. Other supporting structures include the long dorsal sacroiliac (SI) ligament and the sacrotuberous ligament, and the SIJ is stabilized by the latissimus dorsi, thoracolumbar fascia and gluteus maximus [4] [5] [19]-[21]. The SIJ is richly innervated with nociceptive fibers [22] [23]. The ventral portion of the joint is supplied by nerves derived from the ventral rami of some or all of the L2-S2 roots, while the posterior portion is innervated by the dorsal rami of some or all of the L4-S3 roots. There is ongoing debate about the precise innervation of the SIJ, and some authors have also reported significant variation among individuals, making diagnosis and treatment more difficult. Indeed, patient differences, together with the potential for low back pain misdiagnosis, make it essential to establish the SIJ as the source of pain and distinguish it from other pain presentations. A clear diagnosis of "SIJ pain" allows targeted treatment and obviates the need to search for other sources of pain (such as the lumbar facet joints or intervertebral discs) in any one presentation.

Given that SIJ pain can result from direct trauma (such as fracture), abnormal load transfer within the joint (as in sacroiliac joint "dysfunction") or inflammation (as in sacroiliitis) [24], a variety of evidence may be gathered to confirm the SIJ as the source of pain. Yet, clinical assessment and imaging have been shown to be of limited assistance in diagnosing pain of SIJ origin. The International Association for the Study of Pain (IASP) has proposed a three-part criterion for the diagnosis of SIJ pain. In particular, diagnosis requires that 1) the patient has pain in the region of the SIJ, 2) the patient's pain is reproduced by clinical tests that selectively stress the joint, and that 3) the patient's pain is completely relieved by selective delivery of local anesthetic [25].

In the absence of a gold standard for diagnosing pain from the SIJ, the accepted reference standard and evaluation of choice is an anesthetic block. Multiple arguments have been made in favor of and against the diagnostic accuracy of controlled local anesthetic blocks and various guidelines, and systematic reviews maintain that there is evidence to support their use in the diagnosis of SIJ pain [12] [26]. Certainly, dual comparative blocks are a reliable means of eliminating false positive responders, as has been shown in the diagnosis of spinal facet joint pain where controlled medial branch blocks are necessary for diagnosis due to the low specificity of single injections [27]-[31]. However, there is no similarly strong body of evidence that conclusively supports the use of controlled blocks to diagnose pain originating from the SIJ. A few studies have indicated high rates of false positive responses to single blocks, and recent systematic reviews estimate a rate of 20\% [11] [12], meaning that the 
technique has no construct validity unless a control block is used. However, the sparsity of these studies and their methodological variation support further investigation into the accuracy of single blocks.

It is also recognized that technical aspects of SIJ injection can directly influence the diagnostic accuracy of anesthetic blocks [12] [26]. Two well-described factors are correct injection placement and the adequate blocking of SIJ components that cause pain. Poorly placed injections can lead to anesthetic extravasation from the SIJ, blocking structures outside the joint and causing false positive responses. Image guidance during procedures enables accurate injection placement, thereby reducing the risk of anesthetic affecting other structures outside the joint [12]. Adequately, blocking SIJ components is also a fundamental requirement. Many studies rely on intra-articular siting of injections, however there is a substantial contribution to SIJ pain from extra-articular structural components [32]-[35] and therefore it follows that SIJ blocks should be targeted at both intra-articular sites and adjacent structures. Accordingly, in this study, we sought to use a combination of fluoroscopicallyguided intra-articular and DIL injection of local anesthetic to address whether a single positive diagnostic block of the SIJ can be used as the criterion standard that establishes the SIJ as the source of a patient's pain. Or alternatively, is a comparative (control) block necessary? Given the limited and poor evidence available in the literature [11] [36], a large cohort of patients undergoing SIJ injection was assessed over a three-year period. Our objectives were to determine the diagnostic accuracy and the false positive rate of single SIJ anesthetic blocks.

\section{Methods}

\subsection{Study Design}

This was a prospective, observational, open-label study into the accuracy of single SIJ blocks, conducted as part of a practice audit at a private interventional pain management practice and specialty referral centre in Melbourne, Australia. Approximately 5000 patients are seen annually at this practice and the current study included a consecutive series of SIJ injection cases that were attended over a three and a half year period.

\subsection{Patients}

Between January 2007 and August 2010, SIJ/DIL blocks were prospectively administered and evaluated in 1408 consecutive clinic patients presenting with deep somatic pain over the SIJ region. Clinical testing of these patients, using an evidence-based diagnostic algorithm [37] demonstrated they had chronic and significant pain consistent with referred pain from the SIJ (most commonly affecting the buttocks and lower extremities). They had also failed various less invasive therapies, and had typically been assessed with diagnostic medial branch blocks and found not to have facet joint pain.

In keeping with audit procedures, no identifiable data or demographic details were collected and appropriate precautions were taken to protect the privacy and anonymity of all the patients included in this study. Routine consent to undergo procedures was obtained from all participants.

\subsection{Diagnostic Sacroiliac Joint Injection}

Under fluoroscopic guidance, patients presenting with prominent deep somatic pain over the SIJ region were sterilely injected with a contrast fluid to clearly outline the joint and to ensure non-vascular needle placement in the SIJ and DIL. Following this, a combination of $1.5 \mathrm{ml} 0.5 \%$ bupivacaine (or $1.5 \mathrm{ml} 2.0 \%$ lidocaine for control blocks) and $0.5 \mathrm{ml}$ betamethasone was injected into the SIJ and/or DIL. Control blocks, comparing short- and long-lasting injectate, were administered according to current ISIS guidelines for MBBs and used to assess for respective pain relief concordant with the anesthetic used. Typically, when a comparative block was employed, it was administered at least two weeks after the initial diagnostic injection. Blocks were only performed if patients were experiencing their baseline pain levels on the day, thus eradicating possible confounding factors.

\subsection{Outcome Measures}

Following blocks, pain was measured on the 11-point Numerical Pain Rating Scale (NPRS) at half hourly intervals until 2 hours post-injection, at hourly intervals up until 7 hours post-injection, and then daily for $1-2$ weeks following the SIJ/DIL injection. The NPRS is a standard, validated instrument in chronic pain studies that allows patients to subjectively indicate their pain levels on a scale of 0 to 10 , where " 0 " signifies "no pain" and 
" 10 " is "the most intense pain imaginable". Reporting at half-hourly intervals up until 2 hours post-injection was conducted in the clinic, under supervision. Patients were then asked to complete pain score diaries, at home, hourly up until 7 hours post-injection and thereafter, daily for up to 2 weeks. Substantial decreases in presenting SIJ pain score ( $\geq 80 \%$ pain reduction) from $2 \mathrm{hrs}$ following the SIJ/DIL injection were deemed indicative of SIJ pain presentation and recorded as a positive result. The ability to perform previously painful movements was not tested and was not an outcome measure deemed necessary for positive diagnosis. A contingency table was used to determine the precision rate of single anesthetic injections.

\section{Results}

Of the 1408 patients who had undergone a SIJ/DIL injection, complete 1 - 2 week follow up pain scores were available for 1060 (75\%) of the cases. The remaining 348 patients include those who did not return fully completed pain charts for the 2 weeks post-injection $(n=311)$, and equivocal cases $(n=37)$ in whom $\geq 80 \%$ pain relief was achieved but only for 30 minutes or less. In analysing the cases for which complete data were available, a decrease in the pre-injection pain score of $80 \%$ or more for more than two hours post-injection, was taken to be a positive block and considered diagnostic of pain originating from the SIJ.

Of these 1060 available cases, $680(64.2 \%)$ patients were regarded as positive for SIJ pain on the basis of their response to the first SIJ block (Figure 1). Thus, some two thirds of patients presenting with clinical signs consistent with SIJ pain had an initial positive response to a single anesthetic injection. While a significant proportion of these patients elected to not have subsequent injections, control blocks were administered to 293 patients. Most of these individuals $(n=271)$ had a positive response to the first SIJ anesthetic injection, though 22 patients with an initial negative response to SIJ injection opted to receive the control block.

Outcomes indicated that of the 271 patients deemed positive for SIJ pain after the first block, 237 had a subsequent positive response to the second, control injection, confirming their original diagnosis. Therefore, a single, positive anesthetic injection is calculated to be accurate in $87.5 \%$ of cases and, in turn, the false positive proportion for a single diagnostic SIJ block is $12.5 \%$ (Figure 2).

Of the 22 patients who had originally recorded a negative response to their first SIJ injection and then received a second, control SIJ injection, 81.8\% (18 patients) had their negative response confirmed (Figure 2). Using a contingency table, the precision rate of a single sacroiliac joint injection was determined to have a sen-

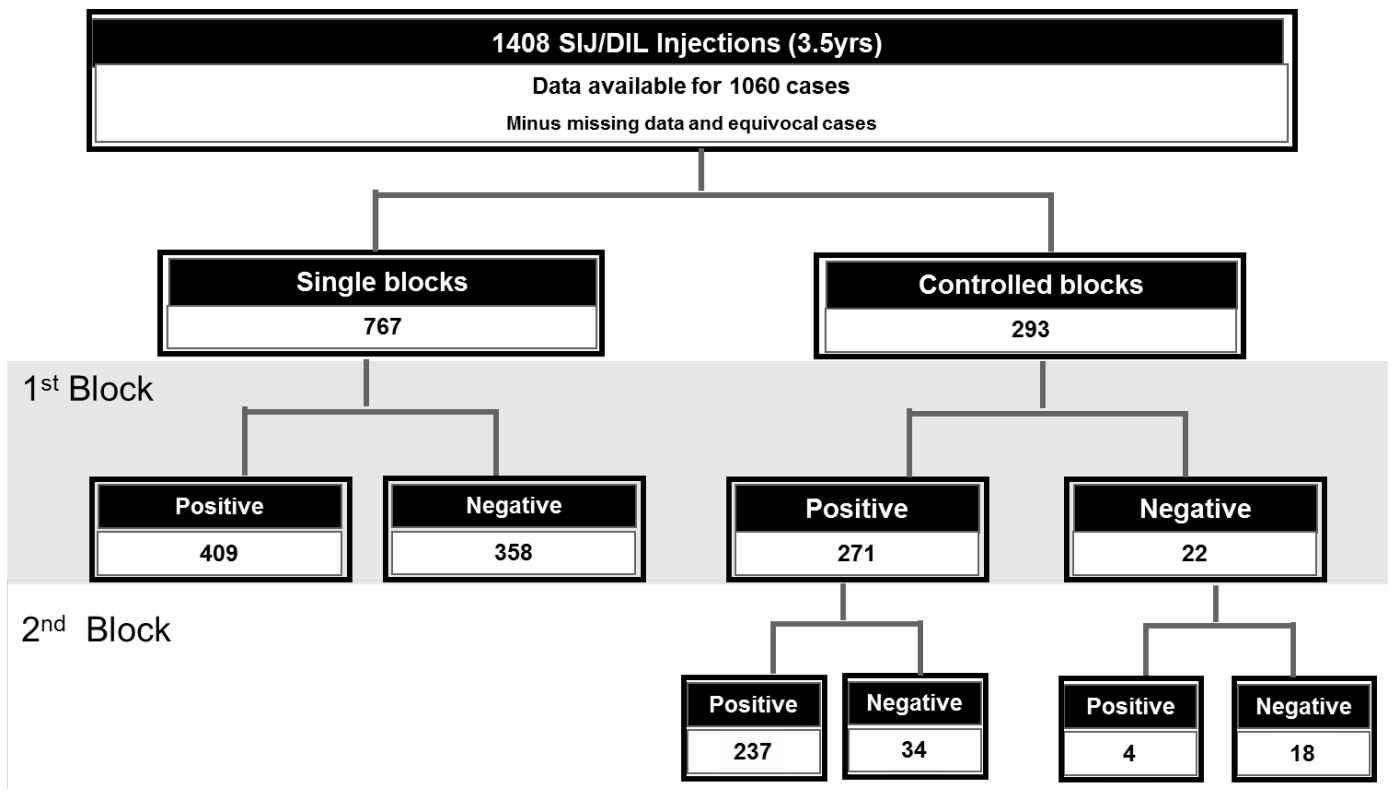

Figure 1. Schema of sacroiliac joint injections over the study period. Of the 1060 reviewed cases, 680 patients (64.2\%) had a positive result to a single sacroiliac joint injection. A second control block injection was administered to 293 patients in total; 271 of which had an initial positive control block and 22 who had a negative control block. Of patients who received a positive response initially, 237 had a positive response to the second injection. 


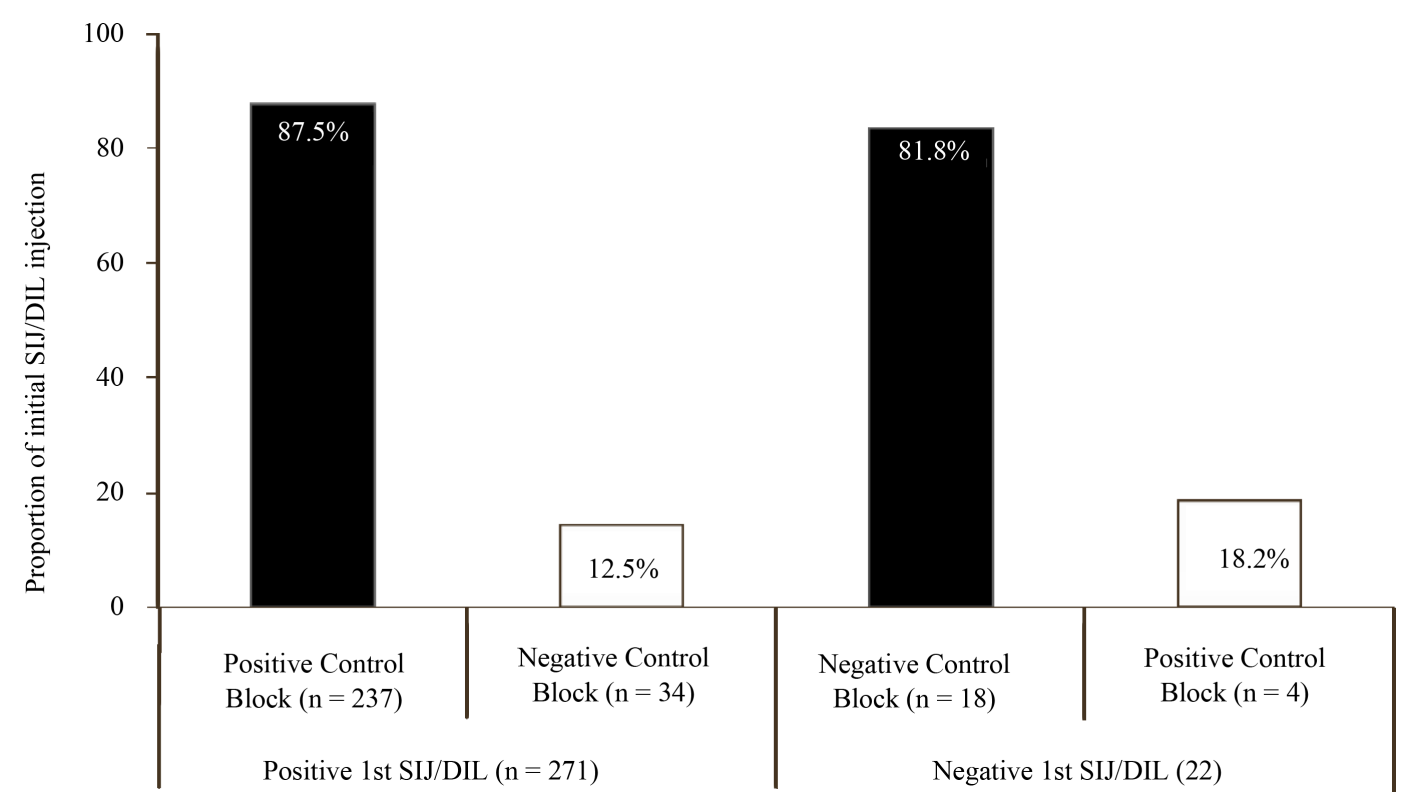

Figure 2. Single sacroiliac joint/deep interosseous ligament injections have an accuracy of greater than $80 \%$. First positive SIJ block had an accuracy of $87.5 \%(\mathrm{n}=237)$ as confirmed by a $2 \mathrm{nd}$ control injection. Where available, of the patients who had a negative response to the first sacroiliac injection, $81.8 \%(\mathrm{n}=18)$ had their diagnosis confirmed by a 2nd control injection.

sitivity of $98.3 \%$ and a specificity of $34.6 \%$ (Table 1). Further analysis indicated a positive predictive value of $87.5 \%$ and negative predictive value of $81.8 \%$, suggesting a high probability of accuracy for both positive and negative outcomes from single anesthetic injections. Taking into account the rates of both correct positive and correct negative diagnoses, overall accuracy of single blocks was calculated to be $87.03 \%$.

\section{Discussion}

It is recognised that there are three major sources of referred low back pain, the SIJ, the lumbar facet joints and the lumbar intervertebral discs. SIJ injection is a commonly used technique for diagnosing SIJ pain. The analgesic response to dual or controlled blocks is the criterion-standard to assess whether or not the patient's pain emanates from the SIJ.

This study assessed single blocks in a cohort of 1408 patients who had undergone one or both of intra-articular and ligamentous injection of bupivacaine and betamethasone, under contrast-mediated fluoroscopic guidance. A substantial decrease in pain on a validated scale following injection was considered a positive block and thus indicative of SIJ pain. In some cases, diagnosis of a positive response was confirmed with a second control block of lidocaine.

The validity of a single block was assessed by comparing results with that of the second, control block. Using a threshold for the positive diagnosis of SIJ pain as greater than or equal to $80 \%$ pain relief from each of the two blocks, there is a diagnostic accuracy of $87.03 \%$ with a single SIJ block. Similar degrees of accuracy $(80.5 \%)$ in smaller cohorts of patients undergoing controlled SIJ blocks have also been demonstrated [22].

A false positive response may arise for a number of reasons, including: inadvertent and unrecognized extravasation of the anesthetic from the intra-articular injection through ventral or dorsal capsular defects; variability of spread from one DIL injection to the next; and placebo response. Previous research states the rate at which patients are falsely diagnosed with SIJ pain when undergoing a single uncontrolled injection is approximately $20 \%$ [11] [38] [39], insinuating that a single, uncontrolled injection is not a robust method of SIJ pain diagnosis. In direct contrast, this study obtained a false positive diagnosis in $12.5 \%$ of patients. The aforementioned studies were from smaller cohorts with most using a less robust positive block criterion of $50 \%$ pain relief, and unlike the current cohort, patients taking part in these studies were often not limited to those presenting with deep somatic pain over their sacroiliac region; they also included those suffering from non-specific low back pain [11]. The lower sample size in combination with the possible extravasation of anesthetic to surrounding tissues, the 
Table 1. Contingency table comparing the precision rates of a single diagnostic sacroiliac joint injection to the criterion standard.

\begin{tabular}{|c|c|c|c|}
\hline \multicolumn{4}{|c|}{ Criterion Standard: Two Positive Blocks Control Block } \\
\hline Initial Block & 293 & Positive & Negative \\
\hline Positive & 271 & 237 & 34 \\
\hline Negative & 22 & 4 & 18 \\
\hline \multicolumn{4}{|c|}{ Analysis Outcomes } \\
\hline \multicolumn{2}{|c|}{ Sensitivity } & \multicolumn{2}{|r|}{$98.3 \%$ (95\% CI: $95.80 \%$ - 99.54\%) } \\
\hline \multicolumn{2}{|c|}{ Specificity } & \multicolumn{2}{|r|}{$34.6 \%$ (95\% CI: $21.97 \%$ - 49.09\%) } \\
\hline \multicolumn{3}{|c|}{ Proportion of Confirmed Positive Diagnoses } & $87.5 \%$ \\
\hline \multicolumn{3}{|c|}{ Proportion of False Positive Diagnoses } & $12.5 \%$ \\
\hline \multicolumn{3}{|c|}{ Proportion of Confirmed Negative Diagnoses } & $81.8 \%$ \\
\hline \multicolumn{3}{|c|}{ Proportion of False Negative Diagnoses } & $18.2 \%$ \\
\hline \multicolumn{2}{|c|}{ Positive Predictive Value } & & $80.9 \%$ \\
\hline \multicolumn{2}{|c|}{ Negative Predictive Value } & & $81.8 \%$ \\
\hline \multicolumn{2}{|c|}{ Overall Accuracy } & & $87.03 \%$ \\
\hline
\end{tabular}

less stringent pain relief criteria, and inclusion of cases without SIJ/DIL localized somatic pain may account for the higher false positive rates obtained when compared to the present study.

The reliability of controlled comparative local anesthetic blocks has also been questioned, as has their use as precision instruments. Issues regarding the quality and quantity of pain relief, the utility of dual blocks, the reference standard used, and a range of other matters have been raised [11]. Even in the case of dual blocks for facet joint diagnosis, for which strong overall evidence exists, diagnostic value has been challenged. A randomized, comparative cost-effectiveness study published by Cohen et al. comparing 0,1 or 2 diagnostic blocks to select patients for lumbar radiofrequency denervation indicated that the patients receiving no blocks had the highest number of overall positive outcomes and the lowest cost per successful procedure [40]. Moreover, while the use of multiple blocks and high pain relief thresholds can reduce the false-positive rate, an unintended effect of such stringent diagnostic criteria may result in a higher rate of false negative results. In turn, safe and effective treatments may be withheld from patients who might otherwise benefit.

In addition to these concerns, the safety of multiple diagnostic blocks is a very real clinical issue. Like most medical procedures there are possible risks, side effects and complications associated with SIJ injection. Whilst these risks are minimal, they do include infection and transient lower extremity numbness due to anesthetization of the lumbosacral nerve roots and sciatic palsy [22]. The elimination of the need for a second injection has obvious benefits in respect of cost, procedural discomfort and minimization of side effects. The high sensitivity and the relatively low false positive rate suggest that a second control block injected into the SIJ and DIL may be unnecessary to confirm the diagnosis of SIJ pain.

A diagnosis of SIJ pain can be useful as it may lead to target specific interventional treatment including radiofrequency neurotomy, prolotherapy and surgery. Successful treatment will confirm the predictive validity of diagnostic SIJ blocks. It is probably reasonable to perform the first two less invasive treatments on a cohort of patients in whom the diagnosis is incorrect in $12.5 \%$ of cases, as it means that there would have been far fewer diagnostic procedures. However, for surgical interventions, control blocks are necessary.

Limitations of this study include a study design in which five pain physicians performed all injections at the same clinic. This may have restricted the generalizability of the findings and future studies may look to include multi-site data to confirm these results. A further limitation is that the study was undertaken as a clinical audit and not a randomized, controlled trial of differing injection strategies. However, although open-label and observational, our study had the advantage of being large and prospective. Another issue to note is incomplete pain score collection and, to a lesser extent, equivocal pain relief outcomes from anesthetic injection which effectively reduced sample size in this study. While some effects on outcomes may have eventuated, we nevertheless had complete data sets for a sizeable cohort of patients. 


\section{Conclusion}

The findings of this study suggest that an initial SIJ/DIL anesthetic injection performed under fluoroscopic guidance with the use of contrast has a sensitivity of $98.3 \%$ and a low false positive rate $(12.5 \%)$, therefore indicating that it is a reliable method of SIJ pain diagnosis. Accordingly, a second control block may be unnecessary in the diagnosis of SIJ pain in chronic pain sufferers.

\section{Disclosure}

No external funding was received for this study. The authors have no relevant interests to disclose.

\section{References}

[1] Katz, V., Schofferman, J. and Reynolds, J. (2003) The Sacroiliac Joint: A Potential Cause of Pain after Lumbar Fusion to the Sacrum. Journal of Spinal Disorders \& Techniques, 16, 96-99. http://dx.doi.org/10.1097/00024720-200302000-00015

[2] Reynolds, H.M. (1980) Three-Dimensional Kinematics in the Pelvic Girdle. The Journal of the American Osteopathic Association, 80, 277-280.

[3] Vleeming, A., Buyruk, K.M., Stoeckart, R., et al. (1992) An Integrated Therapy for Peripartum Pelvic Instability: A Study of the Biomechanical Effects of Pelvic Belts. American Journal of Obstetrics and Gynecology, 166, 1243-1247. http://dx.doi.org/10.1016/S0002-9378(11)90615-2

[4] Vleeming, A., Stoeckart, R., Volkers, A.C., et al. (1990) Relation between Form and Function in the Sacroiliac Joint. Part I: Clinical Anatomical Aspects. Spine, 15, 130-132. http://dx.doi.org/10.1097/00007632-199002000-00016

[5] Vleeming, A., Pool-Goudzwaard, Ac., Hammudoghlu, D., et al. (1996) The Function of the Long Dorsal Sacroiliac Ligament: Its Implication for Understanding Low Back Pain. Spine, 21, 556-562. http://dx.doi.org/10.1097/00007632-199603010-00005

[6] Pool-Goudzwaard, A.Z., Kleinrensink, G.J., Snijders, C.J., et al. (2001) The Sacroiliac Part of the Iliolumbar Ligament. Journal of Anatomy, 199, 457-463. http://dx.doi.org/10.1046/j.1469-7580.2001.19940457.x

[7] Dreyfuss, P., Dreyer, S.J., Cole, A. and Mayo, K. (2004) Sacroiliac Joint Pain. Journal of the American Academy of Orthopaedic Surgeons, 12, 255-265.

[8] Schwarzer, A.C., Aprill, C.N., Derby, R., et al. (1994) The Relative Contributions of the Disc and Zygapophyseal Joint in Chronic Low Back Pain. Spine, 119, 801-806. http://dx.doi.org/10.1097/00007632-199404000-00013

[9] Schwarzer, A.C., Aprill, C.N. and Bogduk, N. (1995) The Sacroiliac Joint in Chronic Low Back Pain. Spine, 20, 31-37. http://dx.doi.org/10.1097/00007632-199501000-00007

[10] Rathmell, J.P. (2008) The Promise of an Effective Treatment for Sacroiliac-Related Low Back Pain. Anesthesiology, 109, 167-168. http://dx.doi.org/10.1097/ALN.0b013e31817fdec8

[11] Simopoulos, T.T., Manchikanti, L., Singh, V., Gupta, S., Hameed, H., Diwan, S. and Cohen, S.P. (2012) A Systematic Evaluation of Prevalence and Diagnostic Accuracy of Sacroiliac Joint Interventions. Pain Physician, 15, E305-E344.

[12] Manchikanti, L., Abdi, S., Atluri, S., Benyamin, R.M., Boswell, M.V., Buenaventura, R.M., et al. (2013) An Update of Comprehensive Evidence-Based Guidelines for Interventional Techniques in Chronic Spinal Pain. Part II: Guidance and Recommendations. Pain Physician, 16, S49-S283.

[13] Slipman, C.W., Lipetz, J.S., Plastaras, C.T., Jackson, H.B., Vresilovic, E.J., Lenrow, D.A. and Braverman, D.L. (2001) Fluoroscopically Guided Therapeutic Sacroiliac Joint Injections for Sacroiliac Joint Syndrome. American Journal of Physical Medicine \& Rehabilitation, 80, 425-432. http://dx.doi.org/10.1097/00002060-200106000-00007

[14] Weksler, N., Velan, G.J., Semionov, M., Gurevitch, B., Klein, M., Rozentsveig, V. and Rudich, T. (2007) The Role of Sacroiliac Joint Dysfunction in the Genesis of Low Back Pain: The Obvious Is Not Always Right. Archives of Orthopaedic and Trauma Surgery, 127, 885-888. http://dx.doi.org/10.1007/s00402-007-0420-x

[15] Buijs, E., Visser, L. and Groen, G. (2007) Sciatica and the Sacroiliac Joint: A Forgotten Concept. British Journal of Anaesthesia, 99, 713-716. http://dx.doi.org/10.1093/bja/aem257

[16] Irwin, R.W. and Harris, M.B. (2004) Concomitant Sacroiliac Joint Pain in Patients with Lumbar Disc Herniation: Case Series. Journal of Surgical Orthopaedic Advances, 13, 224-227.

[17] Cohen, S.P. (2005) Sacroiliac Joint Pain: A Comprehensive Review of Anatomy, Diagnosis, and Treatment. Anesthesia \& Analgesia, 101, 1440-1453. http://dx.doi.org/10.1213/01.ANE.0000180831.60169.EA

[18] Cramer, G. and Ro, C.-S. (2005) The Sacrum, Sacroiliac Joint and Coccyx. In: Cramer, G. and Darby, S., Ed., Basic 
and Clinical Anatomy of the Spine, Spinal Cord and ANS, 2nd Edition, St. Louis, 308-336.

[19] Cattley, P., Winyard, J., Trevaskis, J. and Eaton, S. (2002) Validity and Reliability of Clinical Tests for the Sacroiliac Joint. A Review of Literature. Australasian Chiropractic \& Osteopathy, 10, 73-80.

[20] van Wingerden, J.P., Vleeming, A., Buyruk, H.M. and Raissadat, K. (2004) Stabilization of the Sacroiliac Joint in Vivo: Verification of Muscular Contribution to Force Closure of the Pelvis. European Spine Journal, 13, 199-205. http://dx.doi.org/10.1007/s00586-003-0575-2

[21] van Wingerden, J.P., Vleeming, A. and Ronchetti, I. (2008) Differences in Standing and Forward Bending in Women with Chronic Low Back or Pelvic Girdle Pain: Indications for Physical Compensation Strategies. Spine, 33, E334-E341. http://dx.doi.org/10.1097/BRS.0b013e318170fcf6

[22] Hansen, H.C., Kenzie-Brown, A.M., Cohen, S.P., Swicegood, J.R., Colson, J.D. and Manchikanti, L. (2007) Sacroiliac Joint Interventions: A Systematic Review. Pain Physician, 10, 165-184.

[23] Szadek, K.M., Hoogland, P.V., Zuurmond, W.W., de Lange, J.J. and Perez, R.S. (2008) Nociceptive Nerve Fibers in the Sacroiliac Joint in Humans. Regional Anesthesia and Pain Medicine, 33, 36-43. http://dx.doi.org/10.1097/00115550-200801000-00007

[24] Kapural, L., Nageeb, F., Kapural, M., Cata, J.P., Narouze, S. and Mekhail, N. (2008) Cooled Radiofrequency System for the Treatment of Chronic Pain from Sacroiliitis: The First Case-Series. Pain Practice, 8, 348-354. http://dx.doi.org/10.1111/j.1533-2500.2008.00231.x

[25] Kapural, L., Nageeb, F., Kapural, M., Cata, J.P., Narouze, S. and Mekhail, N. (2009) Diagnostic Validity of Criteria for Sacroiliac Joint Pain: A Systematic Review. The Journal of Pain, 10, 354-368. http://dx.doi.org/10.1016/j.jpain.2008.09.014

[26] Rupert, M.P., Lee, M., Manchikanti, L., Datta, S. and Cohen, S.P. (2009) Evaluation of Sacroiliac Joint Intervention: A Systematic Appraisal of the Literature. Pain Physician, 12, 399-418.

[27] Barnsley, L., Lord, S., Wallis, B. and Bogduk, N. (1993) False-Positive Rates of Cervical Zygapophysial Joint Blocks. The Clinical Journal of Pain, 9, 124-130. http://dx.doi.org/10.1097/00002508-199306000-00007

[28] Atluri, S., Singh, V., Datta, S., Geffert, S., Sehgal, N. and Falco, F.J.E. (2012) Diagnostic Accuracy of Thoracic Facet Joint Nerve Blocks: An Update of the Assessment of Evidence. Pain Physician, 15, E483-E496.

[29] Datta, S., Lee, M., Falco, F.J., Bryce, D.A. and Hayek, S.M. (2009) Systematic Assessment of Diagnostic Accuracy and Therapeutic Utility of Lumbar Facet Joint Interventions. Pain Physician, 12, 437-460.

[30] Falco, F.J.E., Erhart, S., Wargo, B.W., Bryce, D.A., Atluri, S., Datta, S. and Hayek, S.M. (2009) Systematic Review of Diagnostic Utility and Therapeutic Effectiveness of Cervical Facet Joint Interventions. Pain Physician, 12, 323-344.

[31] Rubinstein, S.M. and van Tulder, M. (2008) A Best-Evidence Review of Diagnostic Procedures for Neck and Low-Back Pain. Best Practice \& Research Clinical Rheumatology, 22, 471-482. http://dx.doi.org/10.1016/j.berh.2007.12.003

[32] Borowsky, C.D. and Fagen, G. (2008) Sources of Sacroiliac Region Pain: Insights Gained from a Study Comparing Standard Intra-Articular Injection with a Technique Combining Intra- and Peri-Articular Injection. Archives of Physical Medicine and Rehabilitation, 89, 2048-2056. http://dx.doi.org/10.1016/j.apmr.2008.06.006

[33] Luukanien, R., Nissila, M., Asikainen, E., Sanila, M., Lehtinen, K. and Alantu, A. (1999) Periarticular Corticosteroid Treatment of the Sacroiliac Joint in Patients with Seronegative Spondylarthropathy. Clinical and Experimental Rheumatology, 17, 88-90.

[34] Murakami, E., Tanaka, Y., Aizawa, T., Ishizuka, M. and Kokubun, S. (2007) Effect of Periarticular and Intraarticular Lidocaine Injections for Sacroiliac Joint Pain: Prospective Comparative Study. Journal of Orthopaedic Science, 12, 274-280. http://dx.doi.org/10.1007/s00776-007-1126-1

[35] Cohen, S.P., Chen, Y. and Neufeld, N.J. (2013) Sacroiliac Joint Pain: A Comprehensive Review of Epidemiology, Diagnosis and Treatment. Expert Review of Neurotherapeutics, 13, 99-116. http://dx.doi.org/10.1586/ern.12.148

[36] Hansen, H., Manchikanti, L., Simopoulos, T.T., Christo, P.J., Gupta, S., Smith, H.S., Hameed, H. and Cohen, S.P. (2012) A Systematic Evaluation of the Therapeutic Effectiveness of Sacroiliac Joint Interventions. Pain Physician, 15, E247-E278.

[37] Bogduk, N. (2004) Practice Guidelines: Spinal Diagnostic and Treatment Procedures. International Spine Intervention Society, San Francisco.

[38] Maigne, J.Y., Aivaliklis, A. and Pfefer, F. (1996) Results of Sacroiliac Joint Double Block and Value of Sacroiliac Pain Provocation Tests in 54 Patients with Low Back Pain. Spine, 21, 1889-1892. http://dx.doi.org/10.1097/00007632-199608150-00012

[39] Manchikanti, L., Singh, V., Pampati, V., Damron, K.S., Barnhill, R.C., Beyer, C. and Cash, K.A. (2001) Evaluation of 
the Relative Contributions of Various Structures in Chronic Low Back Pain. Pain Physician, 4, 308-316.

[40] Cohen, S.P., Williams, K.A., Kurihara, C., Nguyen, C., Shields, C., Kim, P., et al. (2010) Multicenter, Randomized, Comparative Cost-Effectiveness Study Comparing 0, 1, and 2 Diagnostic Medial Branch (Facet Joint Nerve) Block Treatment Paradigms before Lumbar Facet Radiofrequency Denervation. Anesthesiology, 113, 395-405.

http://dx.doi.org/10.1097/ALN.0b013e3181e33ae5 